\title{
Usefulness of FDG PET in Primary Bone Tumors
}

\author{
Takashi Yanagawa ${ }^{*},{ }^{1}$ Hideomi Watanabe ${ }^{2}$, Tetsuya Shinozaki ${ }^{1}$ and Kenji Takagishi ${ }^{1}$ \\ ${ }^{I}$ Department of Orthopaedic Surgery, Gunma University Graduate School of Medicine, Maebashi, Japan \\ ${ }^{2}$ Department of Physical Therapy, Gunma University School of Health Science, Maebashi, Japan
}

\begin{abstract}
Positron emission tomography (PET) using $\left[{ }^{18} \mathrm{~F}\right]$ fluorodeoxyglucose (FDG) is a useful modality to examine many kinds of tumors, including primary bone tumors. Malignant bone tumors show higher FDG accumulation than benign tumors and earlier reports mention that FDG-PET can differentiate malignancy from benignancy; however, some benign bone tumors present with high FDG accumulation, which increases false positive rates in FDG-PET. FDG accumulation reflects glucose metabolism and thereby FDG-PET can be used for staging malignant bone tumors, which require a large amount of glucose. Combined with conventional studies, such as magnetic resonance imaging (MRI) and scintigraphy, FDG-PET can more accurately decide the staging. Finally, FDG-PET is also applied to evaluate the chemotherapy response of malignant bone tumors and is expected to predict a patient's prognosis and to help to decide appropriate chemotherapy agents.
\end{abstract}

Keywords: FDG-PET, bone, tumor, grading, staging, SUV.

\section{INTRODUCTION}

Positron emission tomography (PET) using glucose analog $\left[{ }^{18} \mathrm{~F}\right]$ fluorodeoxyglucose (FDG) as a tracer has been widely used in clinical oncology. Intravenously injected FDG is first transported into cells by glucose transporters and then phosphorylated into FDG-6-phosphate by hexokinase in the same way as glucose is phosphorylated into glucose-6-phosphate. While glucose-6-phosphate is further catalyzed in a normal glucose metabolic pathway, FDG-6phosphate is not transformed by phosphoglucose isomerase and therefore remains trapped in cells [1]. The accumulated ${ }^{18}$ F-FDG-6-phosphate reflects glucose uptake and metabolism in the cells. Detecting photons generated via beta decay of ${ }^{18} \mathrm{~F}$, PET can show the distribution of glucose metabolism in a human body [2]. Accumulation of FDG is generally quantified by the standardized uptake value (SUV). Quantification of glucose metabolism by FDG-PET has enabled physicians to differentiate malignancy from benignancy, identify the primary site of carcinoma of unknown origin, decide stages of malignant tumors, and evaluate chemotherapy responses in various cancers. Recently, Medicarereimbursable oncologic FDG-PET applications as initial and subsequent treatment strategies are increasing [3]. In the current article, we review the usefulness of FDG-PET to diagnose and evaluate primary bone tumors.

\section{DIFFERENTIATION OF MALIGNANT FROM BENIGN BONE TUMORS}

Computed tomography (CT) and magnetic resonance imaging (MRI) have contributed to visualize tumor location, tumor extent and the internal structures of tumors; however,

*Address correspondence to this author at the Department of Orthopaedic Surgery, Gunma University Graduate School of Medicine, 3-39-22 Showa, Maebashi, Gunma, 371-8511, Japan; Tel: 1-81-27-220-8269; Fax: 1-81-27220-8275; E-mail: tyanagaw@med.gunma-u.ac.jp these modalities cannot assess tumor activity and metabolism, which are crucial to differentiate malignancy from benignancy and to plan the first operative procedures. Since Warburg reported in 1956 that a cell line that had produced sarcoma in $\mathrm{C} 3 \mathrm{H} / \mathrm{He}$ mice showed higher glucose metabolism than a cell line that had not [4], malignant tumors, such as hepatoma [5, 6], leukemia [7], colon cancer, melanoma, carcinoma of the urinary bladder [6], and so on, have been known to show high glucose metabolism. Some authors have reported higher glucose uptake in malignant musculoskeletal tumors than in benign tumors, and tried to differentiate malignant from benign tumors using an SUV cut-off of 1.93.9. Earlier reports indicate the excellent ability of ${ }^{18} \mathrm{~F}$-FDGPET to differentiate malignant from benign musculoskeletal tumors [8-10] and compression fractures [11]. Recently, however, several authors, including us, have revealed benign tumors with a high SUV, causing a high false-positive rate in trials to differentiate malignancy from benignancy with FDG-PET $[12,13]$. In our two studies with a SUV cut-off of 1.9 , the sensitivity of FDG-PET to correctly diagnose malignancy was $72.7 \%$ and $84.6 \%$, with a specificity of $66.0 \%$ and $80.0 \%$ and an accuracy of $68.0 \%$ and $81.8 \%$, respectively $[14,15]$. To overcome the relatively high false-positive rate in the FDG-PET study, other tracers, such as L- $\left[3-{ }^{18} \mathrm{~F}\right]-\alpha-$ methyltyrosine and $\left[{ }^{11} \mathrm{C}\right]$-choline, have been used and reported to be useful for differentiating malignancy from benignancy $[14,15]$. Table 1 shows procedures reported to be useful for differentiating malignancy from benignancy [16-19]. Benign bone tumors with high SUV by FDG-PET are giant cell tumor, chondroblastoma, Langerhans cell histiocytosis, fibrous dysplasia and osteoid osteoma, a few of which have been included in earlier reports. Among these, fibrous dysplasias have a wide range of SUV from below the cut-off level to a high level, as shown by malignant tumors [12]. It remains unclear why some benign bone tumors show high glucose uptake; however, it may be noteworthy that most of the above benign tumors are giant cells or osteoclasts, which are speculated to originate from macrophages 
Table 1. Reports on Procedures Differentiating Malignancy from Benignancy

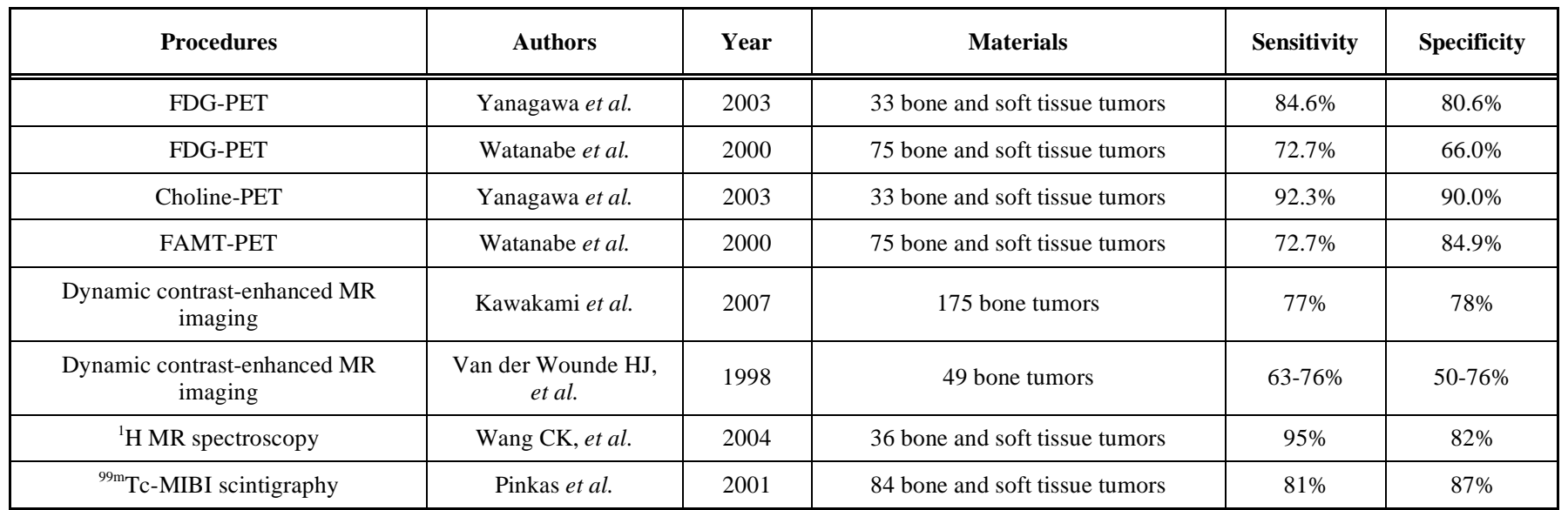

[20]. Kubota et al. reported that FDG was highly accumulated not only in tumors but also in macrophages and granulation tissues surrounding the tumors [21], which might explain why some benign tumors present with a high SUV by FDG-PET.

\section{GRADING AND STAGING OF MALIGNANT BONE TUMORS BY FDG-PET}

The propensity of FDG to accumulate in high metabolic areas has compelled clinicians to apply FDG-PET to tumor grading. Several authors have reported that FDG uptake increased in parallel with the tumor grade in chondrosarcomas, although this could not be a substitute for histopathological assessment due to the wide range and overlap of SUVs in each grade [22-24]. Folpe et al. examined the relationship between FDG-PET SUVs and histopathological findings using the grading system by Unni and Dahlin with a modification [25] and the National Cancer Institute grading system [26] for bone tumors and soft tissue tumors, respectively. A significant difference was revealed between grade I bone and soft tissue sarcomas and grade II and III

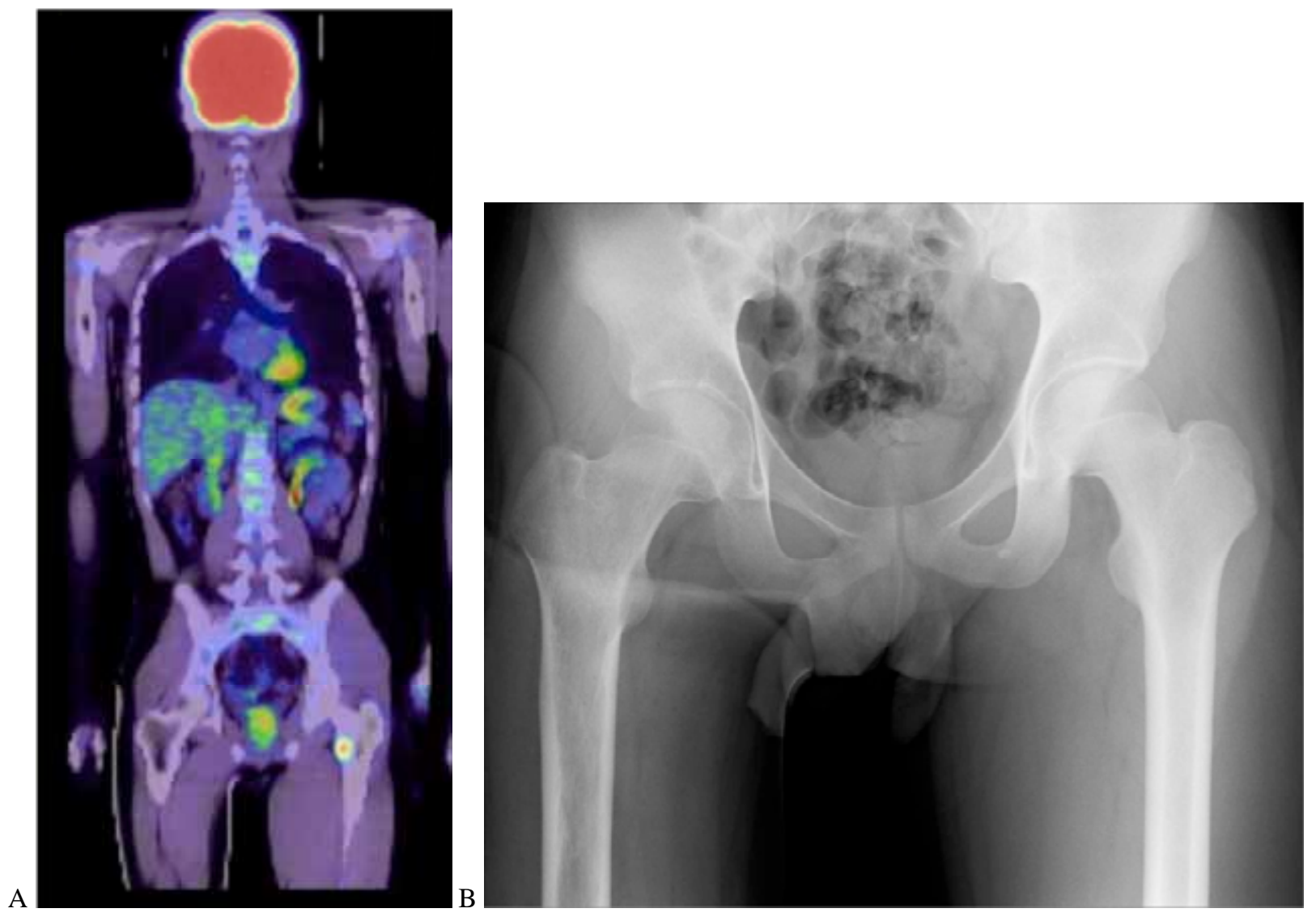

Fig. (1). (A) A 16-year-old patient with osteosarcoma in his lower leg. FDG-PET screening detected metastasis to the lesser trochanter of his femur one year after treatment. (B) Plain X-ray film did not show any lesions in the lesser trochanter at screening. 
SUV by FDG-PET, although there was little difference between benign tumors and grade I sarcomas [27]. They also reported that high SUV was related with hypercellularity, high mitotic activity, the MIB labeling index, and p53 overexpression.

As for tumor staging, a prospective multicenter trial revealed that FDG-PET was superior to conventional imaging modalities, including ultrasound CT, MRI and bone scintigraphy, to detect lymph node involvement and bone manifestation in pediatric sarcoma patients, although CT could depict lung metastases more reliably [28]. Meanwhile, FDG-PET had the same sensitivity as MRI in assessing bone involvement in multiple myeloma, although is superior to whole-body X-ray [29]. Franzius et al. reported that FDGPET was more sensitive than bone scintigraphy in the detection of osseous metastases from Ewing's sarcoma, although less sensitive in the detection of metastases from osteosarcoma [30].

Fig. (1A) is a patient with osteosarcoma of the right lower leg. Metastasis to the left lesser trochanter of his femur was found by FDG-PET screening one year after chemotherapy. He had no pain at screening and an X-ray examination did not show any changes in his femur (Fig. 1B). MRI after FDG-PET revealed a lesion invading the cancerous bone area, not the cortical bone area or the surrounding soft tissues, which explained why a plain X-ray film could not detect the lesion. In this case, FDG-PET seems to be superior to other examinations to screen a whole body and detect metastases. Tateishi et al. described that the accuracy of staging bone sarcoma according to the TNM classification of the International Union against Cancer is improved by combining conventional imaging, including MRI, chest radiography, CT, and bone scintigraphy with PET/CT [31].

\section{EVALUATION OF THERAPY RESPONSES IN MALIGNANT BONE TUMORS}

Evaluating responses to chemotherapy is very important in the treatment of osteogenic sarcoma because the degree of necrosis by chemotherapy is one of the most important prognostic factors [32-34], and a poor response to chemotherapy increases the local failure rate after limb salvage operations [35]. MRI is a good modality to detect tumor necrosis, although its ability to predict chemotherapy responses has a limitation [36]. Schulte et al. showed that a decreased ratio of post- and pre-therapeutic tumor-tobackground in FDG-PET correlated with the amount of tumor necrosis by chemotherapy and FDG-PET could discriminate therapy responders from non-responders in all 27 but 2 patients with a tumor-to-background cut-off level of 0.6 [37]. Hawkins et al. reported that an SUV less than 2.5 after chemotherapy was predictive of progression-free survival in Ewing's sarcoma family of tumors [38]. Recently, we retrospectively examined FDG-PET data for patients with osteosarcoma treated with chemotherapy in our hospital and revealed that the SUV after chemotherapy, not before, could provide prognostic information about patients [39]. Interestingly, immunohistochemical analysis revealed that the expression of autocrine motility factor, which is identical to phosphoglucose isomerase and stimulates tumor cell motility and metastasis [40], significantly correlated with SUVs after chemotherapy. Jones et al. also described that FDG accumulation in soft tissue and musculoskeletal sarcomas decreased after neoadjuvant therapies, although complete absence of FDG uptake could not be achieved. They speculated that the remaining FDG uptake seems to correspond with a pseudocapsule or infiltrating granulation tissues and fibrosis [41]. Fig. (2) shows a patient with osteosarcoma in his left tibia treated with chemotherapy and a subsequent operation. FDG-PET showed that the maximum SUV was 6.94 pre-treatment (A) and 3.74 postchemotherapy (B), suggesting a moderate response to chemotherapy, although persistent FDG uptake was confirmed. Pathological findings of the tumor removed after pre-surgery chemotherapy revealed more than $90 \%$ necrosis and little remaining tumor tissue.

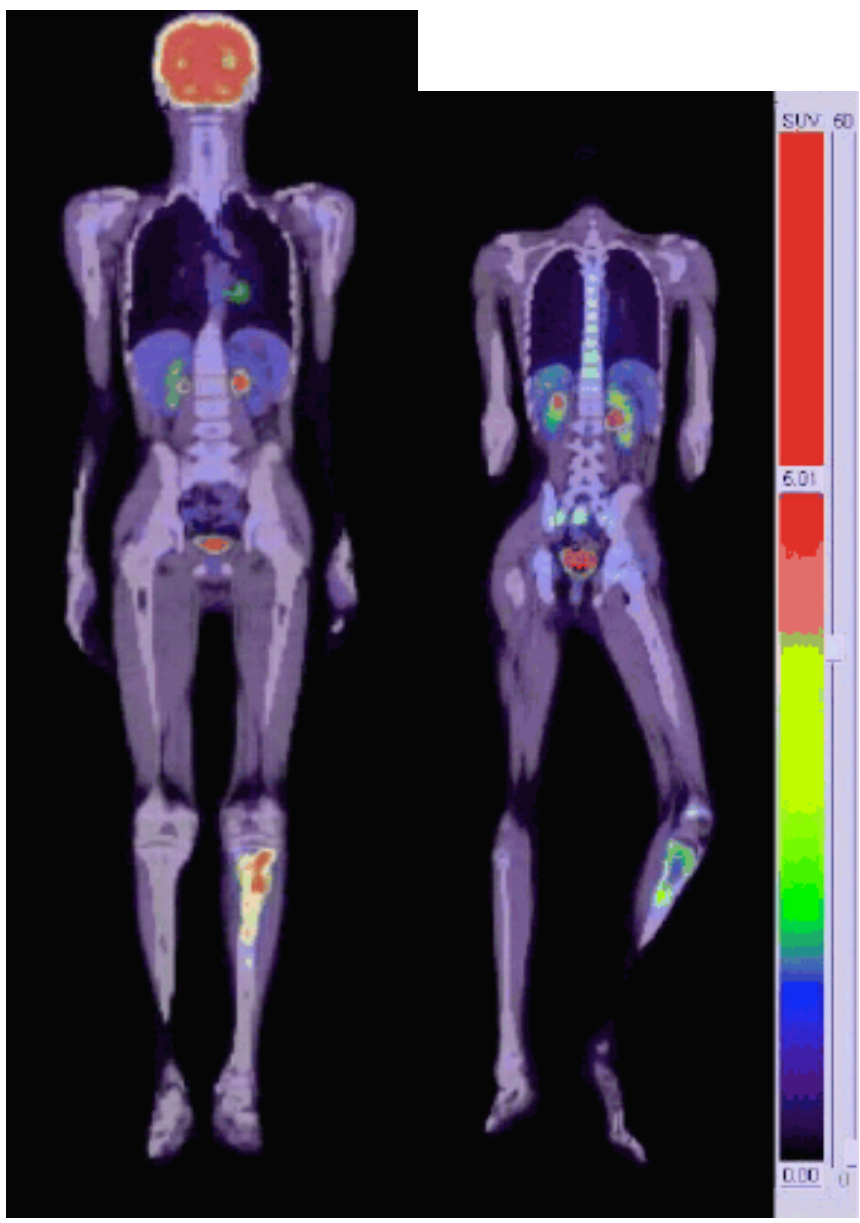

A

B

Fig. (2). A 13-year-old patient with osteosarcoma in his left tibia treated with chemotherapy. FDG-PET showed strong accumulation of FDG with 6.94 SUV pre-treatment (A) and decreased FDG postchemotherapy (B) with 3.74 SUV. Histopathological findings revealed more than $90 \%$ of necrosis in the lesion.

In conclusion, when differentiating malignancy from benignancy, physicians have to keep in mind that some benign bone tumors show high glucose uptake, resulting in high accumulation of FDG. To accurately evaluate bone tumor metastases and dissemination, not only FDG-PET but also other available imaging studies should be used. At present, it can be said that if FDG-PET detects new 
metastatic lesions or SUV does not decrease after chemotherapy, the treatment needs to be reconsidered, while with only FDG-PET, it remains difficult to precisely predict the rate of necrotic lesions in the treated tumor.

\section{ABBREVIATIONS}

$$
\begin{aligned}
& \mathrm{CT}=\text { Computed tomography } \\
& \text { FDG }=\text { Fluorodeoxyglucose } \\
& \text { MRI }=\text { Magnetic resonance imaging } \\
& \text { PET }=\text { Positron emission tomography } \\
& \text { SUV }=\text { Standardized uptake value }
\end{aligned}
$$

\section{ACKNOWLEDGEMENTS}

This work was supported in part by a grant from the Japanese Ministry of Education, Science, Sports and Culture, Grant-in-Aid for Young Scientists (B), 20791026, 2009.

\section{REFERENCES}

[1] Gallagher BM, Fowler JS, Gutterson NI, MacGregor RR, Wan CN, Wolf AP. Metabolic trapping as a principle of oradiopharmaceutical design: some factors resposible for the biodistribution of [18F] 2-deoxy-2-fluoro-D-glucose. J Nucl Med 1978; 19: 1154-61.

[2] van Ginkel RJ, Hoekstra HJ, Pruim J, et al. FDG-PET to evaluate response to hyperthermic isolated limb perfusion for locally advanced soft-tissue sarcoma. J Nucl Med 1996; 37: 984-90.

[3] Centers for Medicare \& Medicate Services [homepage on the Internet] Medicare National Coverage Determinations Manual Chapter 1, Part 4 (Sections 200 - 310.1) Coverage Determinations Available from: http://www.cms.hhs.gov/manuals/downloads/ ncd103c1_Part4.pdf

[4] Warburg O. On the origin of cancer cells. Science 1956; 123: 30914.

[5] Weinhouse S. Glycolysis, respiration, and anomalous gene expression in experimental hepatomas: G.H.A. Clowes memorial lecture. Cancer Res 1972; 32: 2007-16.

[6] Rousset M, Paris H, Chevalier G, Terrain B, Murat JC, Zweibaum A. Growth-related enzymatic control of glycogen metabolism in cultured human tumor cells. Cancer Res 1984; 44: 154-60.

[7] Gottschalk S, Anderson N, Hainz C, Eckhardt SG, Serkova NJ. Imatinib (STI571)-mediated changes in glucose metabolism in human leukemia BCR-ABL-positive cells. Clin Cancer Res 2004; 10: 6661-8.

[8] Dehdashti F, Siegel BA, Griffeth LK, et al. Benign versus malignant intraosseous lesions: discrimination by means of PET with 2-[F-18]fluoro-2-deoxy-D-glucose. Radiology 1996; 200: 243-7.

[9] Kern KA, Brunetti A, Norton JA, et al. Metabolic imaging of human extremity musculoskeletal tumors by PET. J Nucl Med 1988; 29: 181-6.

[10] Feldman F, van Heertum R, Manos C. 18FDG PET scanning of benign and malignant musculoskeletal lesions. Skeletal Radiol 2003; 32: 201-8.

[11] Bredella MA, Essary B, Torriani M, Ouellette HA, Palmer WE. Use of FDG-PET in differentiating benign from malignant compression fractures. Skeletal Radiol 2008; 37: 405-13.

[12] Shin DS, Shon OJ, Han DS, Choi JH, Chun KA, Cho IH. The clinical efficacy of (18)F-FDG-PET/CT in benign and malignant musculoskeletal tumors. Ann Nucl Med 2008; 22: 603-9.

[13] Aoki J, Watanabe H, Shinozaki T, et al. FDG PET of primary benign and malignant bone tumors: standardized uptake value in 52 lesions. Radiology 2001; 219: 774-7.

[14] Watanabe $\mathrm{H}$, Inoue $\mathrm{T}$, Shinozaki $\mathrm{T}$, et al. PET imaging of musculoskeletal tumours with fluorine-18 alpha-methyltyrosine: comparison with fluorine-18 fluorodeoxyglucose PET. Eur J Nucl Med 2000; 27: 1509-17.
[15] Yanagawa $\mathrm{T}$, Watanabe $\mathrm{H}$, Inoue $\mathrm{T}$, et al. Carbon-11 choline positron emission tomography in musculoskeletal tumors: comparison with fluorine-18 fluorodeoxyglucose positron emission tomography. J Comput Assist Tomogr 2003; 27: 175-82.

[16] Pinkas L, Robinson D, Halperin N, et al. 99mTc-MIBI scintigraphy in musculoskeletal tumors. J Nucl Med 2001; 42: 33-7.

[17] Wang CK, Li CW, Hsieh TJ, Chien SH, Liu GC, Tsai KB Characterization of bone and soft-tissue tumors with in vivo $1 \mathrm{H}$ MR spectroscopy: initial results. Radiology 2004; 232: 599-605.

[18] van der Woude HJ, Verstraete KL, Hogendoorn PC, Taminiau AH, Hermans J, Bloem JL. Musculoskeletal tumors: does fast dynamic contrast-enhanced subtraction MR imaging contribute to the characterization? Radiology 1998; 208: 821-8.

[19] Kawakami Y, Kunisada T, Sugihara S, et al. New approach for assessing vascular distribution within bone tumors using dynamic contrast-enhanced MRI. J Cancer Res Clin Oncol 2007; 133: 697703.

[20] Raisz LG RG. Metabolic bone disease and clinically related disorders 2nd. Philadelphia: Saunders; 1990.

[21] Kubota R, Yamada S, Kubota K, Ishiwata K, Tamahashi N, Ido T. Intratumoral distribution of fluorine-18-fluorodeoxyglucose in vivo: high accumulation in macrophages and granulation tissues studied by microautoradiography. J Nucl Med 1992; 33: 1972-80.

[22] Aoki J, Watanabe H, Shinozaki T, Tokunaga M, Inoue T, Endo K. FDG-PET in differential diagnosis and grading of chondrosarcomas. J Comput Assist Tomogr 1999; 23: 603-8.

[23] Brenner W, Conrad EU, Eary JF. FDG PET imaging for grading and prediction of outcome in chondrosarcoma patients. Eur J Nucl Med Mol Imaging 2004; 31: 189-95.

[24] Lee FY, Yu J, Chang SS, Fawwaz R, Parisien MV. Diagnostic value and limitations of fluorine-18 fluorodeoxyglucose positron emission tomography for cartilaginous tumors of bone. J Bone Joint Surg Am 2004; 86-A: 2677-85.

[25] Unni KK, Dahlin DC. Dahlin's Bone Tumors: General Aspects and Data on 11,087 Cases. Philadelphia: Lippincott-Raven, 1996.

[26] Costa J, Wesley RA, Glatstein E, Rosenberg SA. The grading of soft tissue sarcomas. Results of a clinicohistopathologic correlation in a series of 163 cases. Cancer 1984; 53: 530-41.

[27] Folpe AL, Lyles RH, Sprouse JT, Conrad EU, 3rd, Eary JF. (F-18) fluorodeoxyglucose positron emission tomography as a predictor of pathologic grade and other prognostic variables in bone and soft tissue sarcoma. Clin Cancer Res 2000; 6: 1279-87.

[28] Volker T, Denecke T, Steffen I, et al. Positron emission tomography for staging of pediatric sarcoma patients: results of a prospective multicenter trial. J Clin Oncol 2007; 25: 5435-41.

[29] Nanni C, Zamagni E, Farsad M, et al. Role of 18F-FDG PET/CT in the assessment of bone involvement in newly diagnosed multiple myeloma: preliminary results. Eur J Nucl Med Mol Imaging 2006; 33: $525-31$

[30] Franzius C, Sciuk J, Daldrup-Link HE, Jurgens H, Schober O. FDG-PET for detection of osseous metastases from malignant primary bone tumours: comparison with bone scintigraphy. Eur J Nucl Med 2000; 27: 1305-11.

[31] Tateishi U, Yamaguchi U, Seki K, Terauchi T, Arai Y, Kim EE. Bone and soft-tissue sarcoma: preoperative staging with fluorine 18 fluorodeoxyglucose PET/CT and conventional imaging. Radiology 2007; 245: 839-47.

[32] Bramer JA, van Linge JH, Grimer RJ, Scholten RJ. Prognostic factors in localized extremity osteosarcoma: a systematic review. Eur J Surg Oncol 2009;

[33] Davis AM, Bell RS, Goodwin PJ. Prognostic factors in osteosarcoma: a critical review. J Clin Oncol 1994; 12: 423-31.

[34] Bielack SS, Kempf-Bielack B, Delling G, et al. Prognostic factors in high-grade osteosarcoma of the extremities or trunk: an analysis of 1,702 patients treated on neoadjuvant cooperative osteosarcoma study group protocols. J Clin Oncol 2002; 20: 776-90.

[35] Bielack SS, Kempf-Bielack B, Winkler K. Osteosarcoma: relationship of response to preoperative chemotherapy and type of surgery to local recurrence. J Clin Oncol 1996; 14: 683-4.

[36] Lawrence JA, Babyn PS, Chan HS, Thorner PS, Pron GE, Krajbich IJ. Extremity osteosarcoma in childhood: prognostic value of radiologic imaging. Radiology 1993; 189: 43-7.

[37] Schulte M, Brecht-Krauss D, Werner M, et al. Evaluation of neoadjuvant therapy response of osteogenic sarcoma using FDG PET. J Nucl Med 1999; 40: 1637-43. 
[38] Hawkins DS, Schuetze SM, Butrynski JE, et al. [18F]Fluorodeoxyglucose positron emission tomography predicts outcome for Ewing sarcoma family of tumors. J Clin Oncol 2005; 23: 8828-34.

[39] Sato J, Yanagawa T, Dobashi Y, Yamaji T, Takagishi K, Watanabe H. Prognostic significance of $18 \mathrm{~F}-\mathrm{FDG}$ uptake in primary osteosarcoma after but not before chemotherapy: a possible association with autocrine motility factor/phosphoglucose isomerase expression. Clin Exp Metastasis 2008; 25: 427-35.
[40] Watanabe H, Takehana K, Date M, Shinozaki T, Raz A. Tumor cell autocrine motility factor is the neuroleukin/phosphohexose isomerase polypeptide. Cancer Res 1996; 56: 2960-3.

[41] Jones DN, McCowage GB, Sostman HD, et al. Monitoring of neoadjuvant therapy response of soft-tissue and musculoskeletal sarcoma using fluorine-18-FDG PET. J Nucl Med 1996; 37: 143844 .

Received: May 15, 2009

Revised: December 09, 2009

Accepted: December 18, 2009

(c) Yanagawa et al.; Licensee Bentham Open.

This is an open access article licensed under the terms of the Creative Commons Attribution Non-Commercial License (http://creativecommons.org/licenses/by$\mathrm{nc} / 3.0 /$ ), which permits unrestricted, non-commercial use, distribution and reproduction in any medium, provided the work is properly cited. 